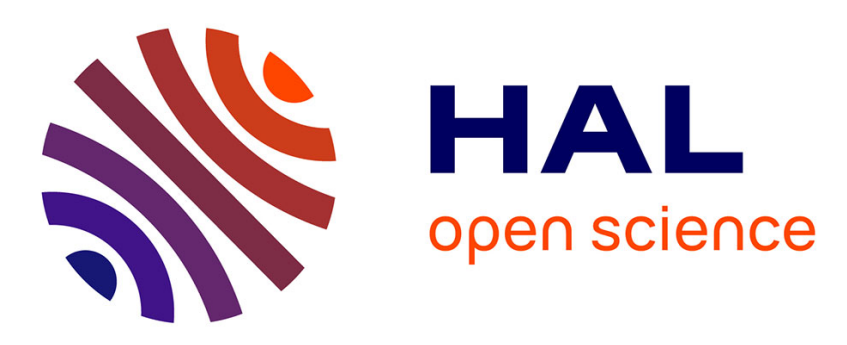

\title{
Twisting Induces Ferromagnetism in Homometallic Clusters
}

Ghenadie Novitchi, Sergi Vela, Guillaume Pilet, Cyrille Train, Vincent Robert

\section{To cite this version:}

Ghenadie Novitchi, Sergi Vela, Guillaume Pilet, Cyrille Train, Vincent Robert. Twisting Induces Ferromagnetism in Homometallic Clusters. Dalton Transactions, 2017, 46 (34), pp.11154-11158. $10.1039 / \mathrm{c} 7 \mathrm{dt} 02360 \mathrm{j}$. hal-01593496

\section{HAL Id: hal-01593496 https://hal.science/hal-01593496}

Submitted on 27 Sep 2017

HAL is a multi-disciplinary open access archive for the deposit and dissemination of scientific research documents, whether they are published or not. The documents may come from teaching and research institutions in France or abroad, or from public or private research centers.
L'archive ouverte pluridisciplinaire HAL, est destinée au dépôt et à la diffusion de documents scientifiques de niveau recherche, publiés ou non, émanant des établissements d'enseignement et de recherche français ou étrangers, des laboratoires publics ou privés. 


\section{Twisting Induces Ferromagnetism in Homometallic Clusters}

Ghenadie Novitchi, ${ }^{\text {a* }}$ Sergi Vela, ${ }^{b}$ Guillaume Pilet, ${ }^{c}$ Cyrille Train, ${ }^{a}$ Vincent Robert ${ }^{\mathrm{b*}}$

A helical chiral cluster bridging two sets of $\mathrm{Cu}_{2}$ units is reported. The two double-strand ligands induce a distorted tetrahedral environment for one of the two copper(II) ions whereas the second one remains in a standard octahedral environment. Magnetic measurements and wavefunction calculations demonstrate that the copper(II) centres are ferromagnetically coupled $\left(J=7.7 \mathrm{~cm}^{-1}\right)$. This ligand-driven ferromagnetic interaction thus appears as a proof-of-concept of an innovative strategy towards high-spin clusters.

Increasing the spin value in the ground state (GS) of polymetallic coordination clusters was and remains one of the major concerns in molecular magnetism. ${ }^{1}$ The ferrimagnetic strategy, that is an antiferromagnetic (AFM) exchange interaction with uncompensated up and down spins, is the most widely used strategy because AFM exchange interaction occurs as soon as the so-called magnetic orbitals (MOs) overlap insuring the domination of superexchange and kinetic exchange mechanisms over potential exchange mechanisms. $\ddagger^{a}$ Nonetheless, a ferromagnetic (FM) exchange interaction leads to the highest possible GS spin value and can therefore appear as the most natural route towards high spin clusters. The first ${ }^{2}$ and still most common strategy to achieve orthogonality of the magnetic orbitals (FM coupling) is to use heterospin pairs., ${ }^{3,4}$ Architectures based on homospin units are more scarce: ${ }^{1,5-11}$ in such dinuclear complexes or cubanes, the ferromagnetic interaction arises from $\mathrm{M}-\mathrm{O}-\mathrm{M}$ angles close to $90^{\circ},{ }^{12-14}$ ensuring the orthogonality of the magnetic orbitals in much the same way as in divalent metal oxides governed by Goodenough-Kanamori rules.

Moreover, since the discovery of DNA double-stranded helical structure ${ }^{15}$ chemists have made many efforts to design and synthesize helical systems. ${ }^{16-27}$ From the early days of $A$. Werner, ${ }^{28}$ coordination complexes are known to favour helical structures. This possibility has been extended to polynuclear helical complexes (helicates) ${ }^{22-25,}$ 29-33 and, more recently, to Metal-Organic Framework. ${ }^{34}$

In the present contribution, the ligand is indeed designed to form upon its expected twisting a helical shaped tetranuclear copper(II) cluster $\left[\mathrm{Cu}_{4}\left(\mathrm{~L}_{\mathrm{B}}\right)_{2}\right]$. Single-crystal $\mathrm{X}$-ray diffraction demonstrates that the cluster has a double-strand helical structure where the copper(II) ions are in two complementary environments. A FM exchange interaction between the magnetic centres is demonstrated by magnetometry. The origin of this interaction is thoroughly studied by $a b$ initio calculations.

The synthesis (details in SI) of the cluster is a three-step process: i) The grafting of a proline moiety onto 3(methylchloride)-1-carboxaldehydephen-2-ol to yield 2hydroxy-3-methyl-(S)-pyrrolidine-2-carboxylate-5-

methylbenzaldehyde $\left(\mathrm{H}_{2} \mathrm{~L}_{\mathrm{A}}\right)$; ii) the complexation of this tridentate chiral proligand to copper(II) ions; ${ }^{35,}{ }^{36}$ iii) taking advantage of the free aldehyde of $\left[\mathrm{CuL}_{A}\left(\mathrm{H}_{2} \mathrm{O}\right)_{2}\right]$, this complex is reacted with di(4-aminophenyl)methane in a 2:1 stoichiometry (Fig. 1) to yield the tetranuclear cluster $\left[\mathrm{Cu}_{4}\left(\mathrm{~L}_{\mathrm{B}}\right)_{2}\right]$.
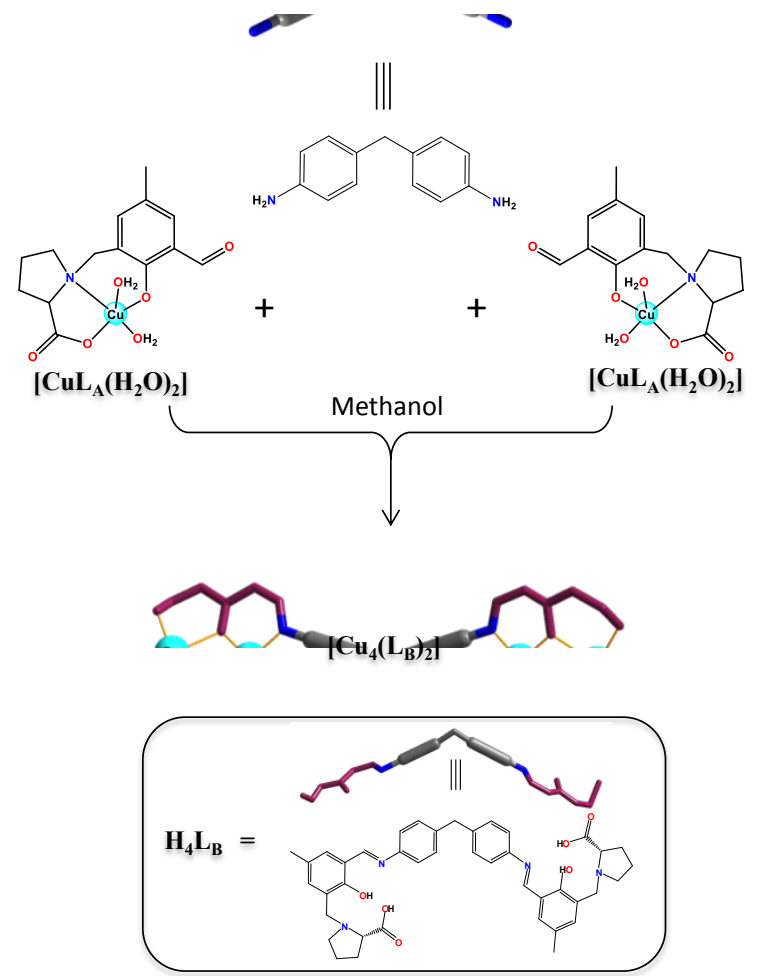

Figure 1. Synthesis of $\left[\mathrm{Cu}_{4}\left(\mathrm{~L}_{\mathrm{B}}\right)_{2}\right]$

According to single crystal X-ray diffraction, $\left[\mathrm{CuL}_{\mathrm{A}}\left(\mathrm{H}_{\mathbf{2}} \mathrm{O}\right)_{2}\right]$ is chiral (Flack parameter equals to $0.05(2)$ ) and has a mononuclear structure with a square-pyramidal (SP) copper $\left\{\mathrm{Cu}\left(\mathrm{NO}_{4}\right)\right\}$ centre. The three coordinating atoms of the tridentate ligand $\mathbf{L}_{\mathbf{A}}{ }^{2-}$ are in the basal plane of the pyramid and the apical position is occupied by a water molecule located at $2.443 \AA$. This contrasts with the situation observed for cobalt(II) (Fig. S1). In this latter case, the preference of cobalt(II) for hexacoordinated environment leads to a 1D coordination polymer. The insolubility of this polymer prevented its use in the third step of the synthesis. The copper(II) derivative $\left[\mathrm{Cu}_{4}\left(\mathrm{~L}_{\mathrm{B}}\right)_{2}\right]$ obtained after this third step crystalizes in the non-centrosymmetric space group $P 2_{1}$ (Flack parameter equals to $0.045(7))$. The compound consists in phenoxo-bridged dicopper(II) units held together by two fully deprotonated $\mathrm{L}_{\mathrm{B}}{ }^{4-}$ polytopic Schiff base ligands that are formed during the condensation reaction (Fig. 2). The separation distance between the two copper(II) dimers is $\approx 11.9 \AA$. The diphenylmethane fragments $\left(\mathrm{PhCH}_{2} \mathrm{Ph}\right)$ are twisted yielding a metalhelicate. 

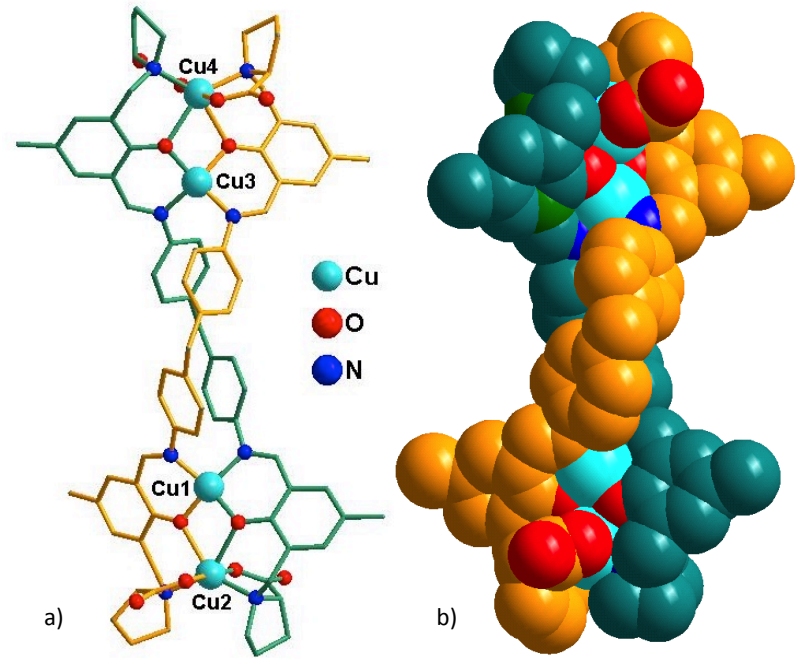

Figure 2. Molecular structure of $\left[\mathrm{Cu}_{4}\left(\mathrm{~L}_{\mathrm{B}}\right)_{2}\right]$ using balls and sticks (a) and space-filling (b) models.

The generation of such helical structure is typical of Schiff-base complexes containing a diphenylmethane fragment. ${ }^{37-41}$ Moreover, guided by the enantiopurity of the proline, only one type of helices is present in the crystals. The environment of the metal ions is deeply modified during the last step of the synthesis. The outer copper(II) centres (Cu2 and Cu4 in Fig. 2) are coordinated in a bis(tridentate) manner by the proline/phenoxo moieties of two $\mathrm{L}_{\mathrm{B}}{ }^{4-}$ ligands: two nitrogen and two oxygen atoms from the carboxylate groups of the Lproline fragments and two oxygen atoms from the phenolate groups located further away from the copper(II) centres ( $d_{\text {Cuz-O }}$ $=2.384 \AA ; \mathrm{d}_{\mathrm{CU} 4-\mathrm{O}}=2.441 \AA$ ). The corresponding $\left\{\mathrm{N}_{2} \mathrm{O}_{4}\right\}$ distorted octahedral $(\mathrm{Oh})$ environment has a symmetry close to $\mathrm{C}_{2 \mathrm{v}}$. In contrast, the inner copper(II) centres (Cu1 and Cu3 in Fig. 2) are coordinated in a bis(bidentate) manner: two oxygen atoms from the phenolate groups and two nitrogen ones from the imine functions. The corresponding $\left\{\mathrm{N}_{2} \mathrm{O}_{2}\right\}$ environment can be seen as a flattened tetrahedron (Td), the angles between the $\mathrm{N}-\mathrm{Cu}-\mathrm{N}$ and $\mathrm{O}-\mathrm{Cu}-\mathrm{O}$ planes being $42.71(2)^{\circ}$ and $47.96(2)^{\circ}$. From the structure resolution, it appears that the condensation reaction deeply influences the coordination of the copper(II) ions: the newly formed bidentate part of $\mathbf{L}_{B}{ }^{4-}$ have replaced the two coordinated water molecules initially present around copper(II) ions and, from four five-coordinated copper(II) centres, one obtains two six- and two four-coordinated metal centres. Most importantly, the expected twist of the $\mathbf{L}_{B}{ }^{4-}$ ligands ${ }^{37-41}$ leads to an original tetrahedral environment for Cu1 and Cu3.

The Circular Dichroism (CD) spectra of $\mathrm{H}_{2} \mathrm{~L}_{A},\left[\mathrm{CuL}_{A}\left(\mathrm{H}_{2} \mathbf{O}\right)_{2}\right]$ and $\left[\mathrm{Cu}_{4}\left(\mathrm{~L}_{\mathrm{B}}\right)_{2}\right]$ recorded in solution confirm the stereoselectivity of the whole synthetic process. The $C D$ spectra of $\left[\mathrm{Cu}_{4}\left(\mathrm{~L}_{\mathrm{B}}\right)_{2}\right]$ in $\mathrm{CHCl}_{3}$ and methanol (see Fig. S12) have similar shapes and are stable in time. The two signals at 660 and $550 \mathrm{~nm}$ with negative Cotton effect can be associated to absorption bands related to $d-d$ transitions for tetrahedral and octahedral copper(II) centres, respectively. This evidence indicates that chiral metalhelicates are present in solution, mainly in one of its enantiomeric form.

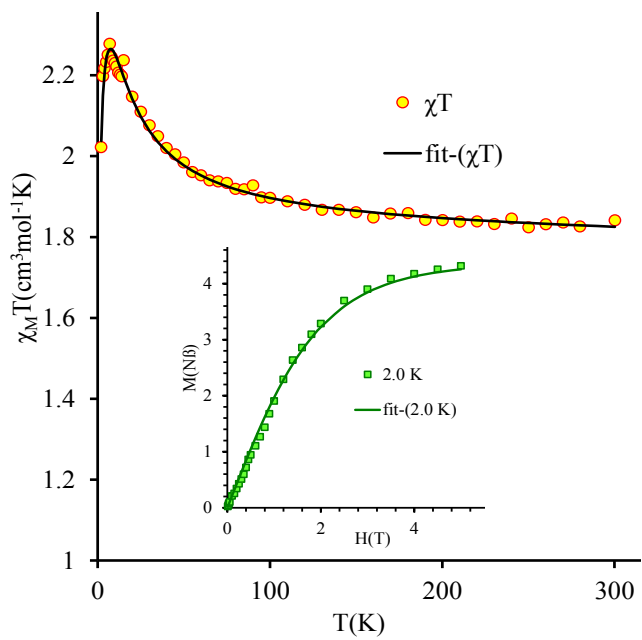

Figure 3. $\chi_{M} T$ versus $T$ plot of $\left[\mathrm{Cu}_{4}\left(\mathrm{~L}_{\mathrm{B}}\right)_{2}\right]$. Insert plot is the magnetisation measurements at $2 \mathrm{~K}$. The solid lines are the best fits according to the model given in the text.

The molar magnetic susceptibility $\chi_{M}$ of tetranuclear copper(II) cluster $\left[\mathrm{Cu}_{4}\left(\mathrm{~L}_{\mathrm{B}}\right)_{2}\right]$ was investigated in the 2 -300K temperature range. The temperature dependence of the $\chi_{M} T$ product is shown in Fig. 3. At room temperature, the $\chi_{M} T$ product is equal to $1.84 \mathrm{~cm}^{3} \mathrm{~mol}^{-1} \mathrm{~K}$ and increases upon cooling to reach $2.28 \mathrm{~cm}^{3} \mathrm{~mol}^{-1} \mathrm{~K}$ at $7 \mathrm{~K}$. Below $7 \mathrm{~K}$, the $\chi_{M} T$ value decreases down to $2.02 \mathrm{~cm}^{3} \mathrm{~mol}^{-1} \mathrm{~K}$ at $2 \mathrm{~K}$. The $\chi_{M} T$ product at room temperature is higher than the theoretically value expected for four isolated $\mathrm{S}=1 / 2$ with $g=2\left(1.5 \mathrm{~cm}^{3} \mathrm{~mol}^{-1} \mathrm{~K}\right)$. Associated with the progressive increase of $\chi_{M} T$ when the temperature is lowered, this is indicative of dominant FM interactions between the metal centres in $\left[\mathrm{Cu}_{4}\left(\mathrm{~L}_{\mathrm{B}}\right)_{2}\right]$. The decrease of the $\chi_{M} T$ product at low temperature is associated to weaker AFM interactions also present in the system.

Based on the X-ray analysis, the tetranuclear core in $\left[\mathrm{Cu}_{4}\left(\mathrm{~L}_{\mathrm{B}}\right)_{2}\right]$ can be separated in two magnetically independent dicopper(II) systems. Moreover, given the similarities of the coordination environments in both ends of $\left[\mathrm{Cu}_{4}\left(\mathrm{~L}_{\mathrm{B}}\right)_{2}\right]$, the two dinuclear units are assumed to display the same magnetic behaviour. Accordingly, the magnetic properties of $\left[\mathrm{Cu}_{4}\left(\mathrm{~L}_{\mathrm{B}}\right)_{2}\right]$ were analysed with the isotropic spin-Hamiltonian $H=-2 J\left(S_{1} S_{2}+S_{3} S_{4}\right)$ where $J$ is the exchange interaction parameter between two neighbouring copper(II) ions and $S_{1}-S_{4}$ are the spins operators associated with $\widehat{S_{1}}-\widehat{S}_{4}=1 / 2$ spin value. The model has been complemented with an additional parameter $z J^{\prime}$ to take into account the AFM interaction between the dinuclear units. The best set of parameters obtained using this model is $J=+7.7 \pm$ $0.4 \mathrm{~cm}^{1} ; g=2.200 \pm 0.005, z J^{\prime}=-0.10 \pm 0.01 \mathrm{~cm}^{1}{ }^{1 \neq \mathrm{b}}$ The presence of FM exchange interactions is supported by magnetisation data (see inset in Fig. S4) which was analysed as a sum of two Brillouin functions with $S=1$ and $g=2.185 \pm$ 0.015 . In both cases, the $g$-factor is the mean value for the four $\mathrm{Cu}^{\prime \prime}$ centres. Finding a FM exchange interaction between two copper(II) centres is rather uncommon in the literature. ${ }^{8,9}$ Based on Kahn's model, ${ }^{3}$ this must be related to the different coordination environments of the two copper(II) centres that leads to the orthogonality of the MOs.

Table 1. Calculated exchange coupling constant values (in $\mathrm{cm}^{-1}$ ) and amplitudes of the leading contributions in the triplet wavefunctions of subunit $\mathbf{A}$. The subscripts $\mathrm{Oh}$ and $\mathrm{Td}$ refer to the copper(II) centre implied in the LMCTs.

\begin{tabular}{cccccc}
\hline & $J$ & $\mid \Psi \mathrm{CAS}>$ & $\left|\mathrm{LMCT}_{(\mathrm{Td})}\right\rangle$ & $\left|\mathrm{LMCT}_{(\mathrm{Td})}\right\rangle$ & $\left|\mathrm{LMCT}_{(\mathrm{Oh})}\right\rangle$ \\
$\mathrm{CAS}-\mathrm{Cl}$ & +1.4 & 1.0 & 0.0 & 0.0 & 0.0 \\
$\mathrm{CAS}+\mathrm{S}$ & +2.5 & $\approx 1.0$ & $\ldots$ & $\ldots$ & $\ldots$ \\
$\mathrm{CAS}+\mathrm{DDCl}$ & +6.7 & 0.954 & 0.036 & 0.022 & 0.046 \\
\hline
\end{tabular}



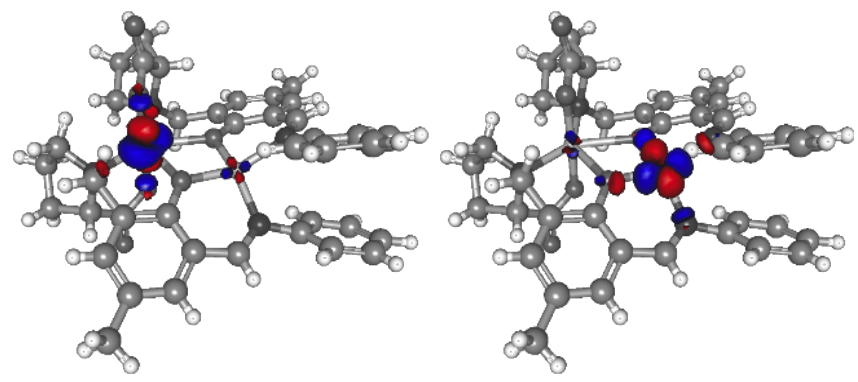

Figure 4. Active MOs extracted from a CAS[2,2]SCF calculation for the triplet state on fragment $A$. The active MOs on fragment B are very similar (see SI).

To test this interpretation, DFT and DDCl calculations have been performed to analyse the magnetic behaviour of $\left[\mathrm{Cu}_{4}\left(\mathrm{~L}_{\mathrm{B}}\right)_{2}\right]$. First, DFT calculations confirm the small inter-dimer magnetic interaction (less than $0.2 \mathrm{~cm}^{-1}$, see $\mathrm{SI}$ ). Therefore, the magnetism of $\left[\mathrm{Cu}_{4}\left(\mathrm{~L}_{\mathrm{B}}\right)_{2}\right]$ can be described as two nearly independent dicopper(II) units referred to as $\mathbf{A}$ and $\mathbf{B}$. DDCl calculations on pairs $\mathbf{A}$ and $\mathbf{B}$ confirm the FM character of the exchange interaction within the dinuclear units $(J=6.7$ and 8.1 $\mathrm{cm}^{-1}$ for $\mathbf{A}$ and $\mathbf{B}$, respectively). The mean computed value (7.4 $\mathrm{cm}^{-1}$ ) is in excellent agreement with the fitted $J$ value $(7.7$ $\mathrm{cm}^{-1}$, see above). Interestingly, the calculations are able to distinguish two exchange interaction parameters in $\mathbf{A}$ and $\mathbf{B}$ despite the similar metrics in both subunits.

Moreover, these calculations allow us to investigate the different contributions to the singlet-triplet energy-difference: the ligand imposes electronic configurations $t_{2 g} e_{g}{ }^{3}$ and $e^{4} t_{2}{ }^{5}$ on the Oh and flattened Td sites, respectively. Based on Kahn's model, the ligand is thus expected to favour FM behaviour by driving the orthogonality of the magnetic orbitals. Indeed, the singly-occupied $e_{g} d_{z^{2}}$ - and $t_{2} d_{x y}$-type orbitals (localized on the $\mathrm{Oh}$ and Td moieties, respectively) are quasi-perpendicular (see Fig. 4). This analysis is consistent with the positive $J$ value obtained at the CAS-Cl level for dimer $\mathbf{A}\left(+1.4 \mathrm{~cm}^{-1}\right.$ in Table 1$)$.

However, this scenario can be deeply modified as soon as electron correlation effects (charge distributions and spin polarization) are included. ${ }^{42,43}$ In particular, the contributions of the so-called ionic forms (e.g. $\mathrm{t}_{2 \mathrm{~g}} \mathrm{e}_{\mathrm{g}}{ }^{4}-\mathrm{e}^{4} \mathrm{t}_{2}{ }^{4}$ ) entering the singlet CAS- $\mathrm{Cl}$ wavefunction are likely to be enhanced by the $\mathrm{CAS}+\mathrm{S}$ dynamical response. In contrast, the sign of the spin polarization contribution is difficult to predict.xx Such contributions are known to be dominant for bridging ligands (LMCT(Td) entry in Table 1). ${ }^{42}$ Spin polarization slightly stabilizes the triplet state over the singlet. Interestingly, the enhancement of FM is more pronounced at the $\mathrm{DDCl}$ level $\left(+6.7 \mathrm{~cm}^{-1}\right)$ : from Table 1, the LMCT forms which are almost absent at the CAS+S level become important and their stabilization in the triplet state give rise to a complementary FM contribution.

It thus appears that $a b$ initio calculations not only reproduce quantitatively the FM exchange interaction parameter found experimentally in the dicopper(II) units but dig out more complex exchange mechanisms. This latter result underlines that a valence-only vision of exchange interaction is not sufficient to conclude on the origin of FM behaviour for medium-ranged exchange interaction parameter.

In summary, following a three-step synthesis, a new chira tetranuclear helical copper cluster $\left[\mathrm{Cu}_{4}\left(\mathbf{L}_{\mathrm{B}}\right)_{2}\right]$ has been obtained. Upon the expected twisting of the chiral polytopic Schiff-base ligand $\mathbf{L}_{\mathbf{B}}{ }^{4-}$, the copper(II) ions seat in complementary distorted octahedral and tetrahedral coordination sites. This unique Oh-Td pair favours a FM exchange interaction $\left(J_{\text {exp }}=+7.7 \mathrm{~cm}^{-1}\right)$ between the copper(II) ions. Wavefunction-based calculations reproduce quantitatively the experimental magnetic behaviour and indicate that the FM character is due not only to the orthogonality of the magnetic orbitals in such architecture but also to the presence of spin polarization effects and the stabilization of the LMCT forms. The synthetic strategy presented herein extends the scope of existing routes for highspin clusters generation. The twisting ability of Schiff-base complexes containing a diphenylmethane fragment ${ }^{37-41}$ calls for the insertion of other metal ions in such metalhelicates. Moreover, the controlled chirality of these objects combined with their magnetic properties are an open door towards the observation of magneto-chiral effects given that ions with high spin-orbit coupling are introduced in the molecular architecture. ${ }^{44,45}$

\section{Methods.}

The synthetic procedures of synthesis are reported in the SI. The FTIR spectra were obtained using the Nicolet Fourier Transform Infra-Red (FTIR) spectrophotometer is $50 \mathrm{IR}$. The FTIR spectra were recorded in $\mathrm{KBr}$ pellets with 32 scans per spectrum at a resolution of $4 \mathrm{~cm}^{-1}$. UV-vis absorption spectra were recorded on JASCO V770 spectrophotometer, while CD spectra on JASCO J1500 spectrometer. The spectra were measured at room temperature in a cuvette with $10 \mathrm{~mm}$ path length. The ${ }^{1} \mathrm{H},{ }^{13} \mathrm{C}$ NMR spectra were recorded on Bruker Advance II spectrometers at $300\left({ }^{1} \mathrm{H}\right)$ and $75.4\left({ }^{13} \mathrm{C}\right)$ $\mathrm{MHz}$, respectively. The ${ }^{1} \mathrm{H}$ and ${ }^{13} \mathrm{C}$ chemical shifts were referred to the residual signals from the solvent as reference. Deuterated solvent DMSO- $\mathrm{d}_{6}$ was bought from Sigma-Aldrich. Variable-temperature (2.0-300 K) direct current $(d c)$ and magnetic susceptibility and magnetization measurements were carried out on slightly crushed polycrystalline sample with a Quantum Design SQUID magnetometer. The $d c$ susceptibility was measured using an applied field of 0.1 T. The magnetic susceptibility data were corrected for the diamagnetism of the constituent atoms and the sample holder contribution. Single-crystal XRD studies of $\left[\mathrm{CuL}_{A}\left(\mathrm{H}_{2} \mathrm{O}\right)_{2}\right],\left[\mathrm{Co}_{2}\left(\mathrm{~L}_{\mathrm{A}}\right)_{2}\right]$ and $\left[\mathrm{Cu}_{4}\left(\mathrm{~L}_{\mathrm{B}}\right)_{2}\right]$ were performed with a Gemini diffractometer and the related analysis software. ${ }^{46}$ Absorption corrections based on the crystal faces $^{47}$ (analytical, $\left[\mathrm{Co}_{2}\left(\mathrm{~L}_{\mathrm{A}}\right)_{2}\right]$, and $\left[\mathrm{Cu}_{4}\left(\mathrm{~L}_{\mathrm{B}}\right)_{2}\right]$ ) and semi-empirical ${ }^{48}$ (multiscan, $\mathrm{H}_{2} \mathrm{~L}_{\mathrm{A}},\left[\mathrm{CuL}_{\mathrm{A}}\left(\mathrm{H}_{2} \mathrm{O}\right)_{2}\right]$ ) were applied to the data set.Structures were solved by direct methods with the SIR97 program ${ }^{49}$ combined with Fourier difference syntheses and refined against $F$ with the CRYSTALS program. ${ }^{50}$ All atomic displacement parameters for non-hydrogen atoms were refined with anisotropic terms. The hydrogen atoms were located theoretically on the basis of the conformation of the supporting atom and refined by using a riding model. All details are summarized in Table S1.

\section{Notes and references}

$\ddagger^{\mathrm{a}}$ At least when phenomena in the complete active space (CAS) are dominating all the others.

$\ddagger^{\mathrm{b}}$ Given their similarity, any attempt to discriminate the two pairs of magnetic centres lead to an overparametrization of the system.

Acknowledgements: S.V. was supported by a post-doctoral grant of the LabEx-Chemistry of Complex Systems, ANR-10LABX-0026_CSC. The work of G. N. and C. T. was supported by ANR-13-BS08-0016-01.

1. O. Kahn, Angewandte Chemie-International Edition in English, 1985, 24, 834-850.

2. O. Kahn, J. Galy, Y. Journaux, J. Jaud and I. Morgensternbadarau, J. Am. Chem. Soc., 1982, 104, 2165-2176.

3. M. Verdaguer and V. Robert, in Comprehensive Inorganic Chemistry II (Second Edition), ed. K. Poeppelmeier, Elsevier, Amsterdam, 2013, DOI: http://dx.doi.org/10.1016/B978-0-08-097774-4.00819-6, pp. 131-189.

4. E. Ruiz, A. Rodriguez-Fortea, S. Alvarez and M. Verdaguer, Chemistrya European Journal, 2005, 11, 2135-2144.

5. O. Kahn, Inorganica Chimica Acta-Articles, 1982, 62, 3-14.

6. S. Sikorav, I. Bkouchewaksman and O. Kahn, Inorg. Chem., 1984, 23, 490-495.

7. A. Merhi, T. Roisnel, S. Rigaut, C. Train and L. Norel, Crystengcomm, 2014, 16, 9783-9787.

8. C. Aronica, E. Jeanneau, H. El Moll, D. Luneau, B. Gillon, A. Goujon, A. Cousson, M. A. Carvajal and V. Robert, Chemistry-a European Journal, 2007, 13, 3666-3674. 
9. I. Fernandez, R. Ruiz, J. Faus, M. Julve, F. Lloret, J. Cano, X. Ottenwaelder, Y. Journaux and M. C. Munoz, Angewandte ChemieInternational Edition, 2001, 40, 3039-3042.

10. C. Aronica, Y. Chumakov, E. Jeanneau, D. Luneau, P. Neugebauer, A.L. Barra, B. Gillon, A. Goujon, A. Cousson, J. Tercero and E. Ruiz, Chemistry-a European Journal, 2008, 14, 9540-9548.

11. J. Tercero, E. Ruiz, S. Alvarez, A. Rodriguez-Fortea and P. Alemany, J. Mater. Chem., 2006, 16, 2729-2735.

12. E. Ruiz, C. de Graaf, P. Alemany and S. Alvarez, J. Phys. Chem. A 2002, 106, 4938-4941.

13. V. Archana, Y. Imamura, H. Sakiyama and M. Hada, Bull. Chem. Soc. Jpn., 2016, 89, 657-665.

14. D. Venegas-Yazigi, D. Aravena, E. Spodine, E. Ruiz and S. Alvarez, Coord. Chem. Rev., 2010, 254, 2086-2095.

15. J. D. Watson and F. H. C. Crick, Nature, 1953, 171, 737-738.

16. G. Rapenne, B. T. Patterson, J. P. Sauvage and F. R. Keene, Chem. Commun., 1999, DOI: 10.1039/a905135j, 1853-1854.

17. G. Rapenne, C. Dietrich-Buchecker and J. P. Sauvage, J. Am. Chem. Soc., 1999, 121, 994-1001.

18. D. Zhao, T. van Leeuwen, J. Cheng and B. L. Feringa, Nat Chem, 2016, advance online publication.

19. J. F. Ayme, J. E. Beves, D. A. Leigh, R. T. McBurney, K. Rissanen and D. Schultz, Nature Chemistry, 2012, 4, 15-20.

20. J. R. Aldrich-Wright, Nat Chem, 2012, 4, 10-11.

21. M. Albrecht, Nature Chemistry, 2014, 6, 761-762.

22. C. Piguet, Journal of inclusion phenomena and macrocyclic chemistry, 1999, 34, 361-391.

23. C. Piguet, G. Bernardinelli and G. Hopfgartner, Chem. Rev., 1997, 97, 2005-2062.

24. M. Albrecht, Chem. Rev., 2001, 101, 3457-3498.

25. M. Albrecht, Angew. Chem. Int. Ed., 2005, 44, 6448-6451.

26. V. E. Campbell, X. de Hatten, N. Delsuc, B. Kauffmann, I. Huc and J. R. Nitschke, Nature Chemistry, 2010, 2, 684-687.

27. K. Miwa, Y. Furusho and E. Yashima, Nature Chemistry, 2010, 2, 444449.

28. A. Werner, Berichte Der Deutschen Chemischen Gesellschaft, 1911, 44, $1887-1898$

29. J. M. Lehn, A. Rigault, J. Siegel, J. Harrowfield, B. Chevrier and D. Moras, Proc. Natl. Acad. Sci. U.S.A., 1987, 84, 2565

30. J.-M. Lehn, Supramolecular Chemistry,, VCH, Weinheim,, 1995.

31. J.-M. Lehn, in Supramol. Chem., Wiley-VCH Verlag GmbH \& Co. KGaA, 2006, DOI: 10.1002/3527607439.ch1, pp. 1-9.

32. J. W. Steed and J. L. Atwood, Supramolecular chemistry, John Wiley \& Sons, 2009.

33. J.-M. Lehn, Proceedings of the National Academy of Sciences, 2002, 99, 4763-4768.

34. M. Mon, F. Lloret, J. Ferrando-Soria, C. Marti-Gastaldo, D. Armentano and E. Pardo, Angewandte Chemie-International Edition, 2016, 55, 11167-11172.

35. M. N. M. Milunovic, E. A. Enyedy, N. V. Nagy, T. Kiss, R. Trondl, M. A. Jakupec, B. K. Keppler, R. Krachler, G. Novitchi and V. B. Arion, Inorg. Chem., 2012, 51, 9309-9321.

36. A. Dobrova, S. Platzer, F. Bacher, M. N. M. Milunovic, A. Dobrov, G. Spengler, E. A. Enyedy, G. Novitchi and V. B. Arion, Dalton Transactions, 2016, 45, 13427-13439.

37. M. J. Hannon, C. L. Painting and N. W. Alcock, Chem. Commun., 1999, DOI: 10.1039/a905795a, 2023-2024.

38. A. Lavalette, F. Tuna, G. Clarkson, N. W. Alcock and M. J. Hannon, Chem. Commun., 2003, DOI: 10.1039/b308963k, 2666-2667.

39. P. Cucos, F. Tuna, L. Sorace, I. Matei, C. Maxim, S. Shova, R. Gheorghe, A. Caneschi, M. Hillebrand and M. Andruh, Inorg. Chem., 2014, 53, 7738-7747.

40. G. Novitchi, J. P. Costes, J. P. Tuchagues, L. Vendier and W. Wernsdorfer, New J. Chem., 2008, 32, 197-200.

41. F. Habib, J. Long, P.-H. Lin, I. Korobkov, L. Ungur, W. Wernsdorfer, L. F. Chibotaru and M. Murugesu, Chemical Science, 2012, 3, 2158-2164.

42. L. Tenti, D. Maynau, C. Angeli and C. J. Calzado, PCCP, 2016, 18, 18365-18380.

43. J. B. Rota, C. J. Calzado, C. Train and V. Robert, J. Chem. Phys., 2010, 132.

44. C. Train, R. Gheorghe, V. Krstic, L. M. Chamoreau, N. S. Ovanesyan, G. Rikken, M. Gruselle and M. Verdaguer, Nature Materials, 2008, 7, 729-734.

45. R. Sessoli, M. E. Boulon, A. Caneschi, M. Mannini, L. Poggini, F. Wilhelm and A. Rogalev, Nature Physics, 2015, 11, 69-74.

46. CrysAlisPro, v. 1.171.33.46 (rel. 27-08-2009 CrysAlis171.NET), Oxford

Diffraction Ltd.,, 2009.
47. J. Demeulenaer and H. Tompa, Acta Crystallographica, 1965, 19, 1014-+.

48. R. H. Blessing, Acta Crystallographica Section A, 1995, 51, 33-38.

49. A. Altomare, M. C. Burla, M. Camalli, G. L. Cascarano, C. Giacovazzo, A. Guagliardi, A. G. G. Moliterni, G. Polidori and R. Spagna, J. Appl. Crystallogr., 1999, 32, 115-119.

50. D. J. Watkin, Prout, C. K., Carruthers, J. R., Betteridge, P. W., Journal, 1999. 